TITLE:

\title{
Field Observation of Maternal Attendance of Eggs in a Madagascan Snake, Leioheterodon madagascariensis
}

\section{$\operatorname{AUTHOR}(S)$ :}

Mori, Akira; Randriamboavonjy, Tahirihasina Mathieu

\section{CITATION:}

Mori, Akira ...[et al]. Field Observation of Maternal Attendance of Eggs in a Madagascan Snake, Leioheterodon madagascariensis. Current Herpetology 2010, 29(2): 91-95

ISSUE DATE:

2010-12

URL:

http://hdl.handle.net/2433/197269

RIGHT:

(C) 2010 by The Herpetological Society of Japan 


\section{Field Observation of Maternal Attendance of Eggs in a Madagascan Snake, Leioheterodon madagascariensis}

\begin{abstract}
AKIRA MORI ${ }^{1 *}$ AND TAHIRIHASINA MATHIEU RANDRIAMBOAVONJY ${ }^{2}$
\end{abstract}

${ }^{1}$ Department of Zoology, Graduate School of Science, Kyoto University, Sakyo, Kyoto 606-8502, JAPAN

${ }^{2}$ Département de Biologie Animale, Université d'Antananarivo, BP 906

Antananarivo 101, MADAGASCAR

\begin{abstract}
Maternal attendance of eggs is a parental care behavior widespread in snakes, but observations under natural situations are limited. During a radio-tracking study in a dry forest in Madagascar, we located a female Leioheterodon madagascariensis that was attending a clutch of eggs in a cavity below ground. The late embryonic stage of an excavated egg and locations of the female recorded before its discovery with the clutch suggest that the female had been attending the eggs for a relatively long period but with occasional intervals when she left the oviposition site.
\end{abstract}

Key words: Madagascar; Leioheterodon madagascariensis; Nest site; Maternal attendance; Parental care

A growing number of behavioral observations suggest that snakes are more social than previously believed (Somma, 1990; Duvall et al., 1993; Clark, 2004; Shine et al., 2005). Maternal attendance of eggs is a kind of social behavior that has seemingly been underestimated in snakes (Greene et al., 2002). Nonetheless, because of the difficulty in finding natural oviposition sites, evidence of attendance of eggs by wild female snakes is still limited,

* Corresponding author. Tel: +81-75-753-4075;

Fax: +81-75-753-4075;

E-mail address: gappa@ethol.zool.kyoto-u.ac.jp and the extent of maternal investment is largely unclear. Here, we report on a case of maternal attendance of eggs in a Madagascan colubrid snake, Leioheterodon madagascariensis, observed in the field, which suggests the female's relatively long attendance but with occasional intervals of leaving the oviposition site.

Our observations were made at Ampijoroa Forest Station in Ankarafantsika National Park $\left(16^{\circ} 15^{\prime} \mathrm{S}, 46^{\circ} 48^{\prime} \mathrm{E}\right)$, in northwestern Madagascar. This area consists of a deciduous dry forest, where the rainy season usually lasts from November to March (see Mori et al. [2006] for details).

We captured a female $L$. madagascariensis (snout-vent length: $1281 \mathrm{~mm}$; body mass: $595 \mathrm{~g}$ ) on a sandy trail, which is located approximately $130 \mathrm{~m}$ away from the oviposition site mentioned below, on 15 November 2005 . We surgically implanted a radio-transmitter in it (Holohil, AI-2, $16.5 \mathrm{~g}$; for surgical methods, see Reinert and Cundall [1982] and Nishimura et al. [1995]) and released it at the site of initial capture on 22 November 2005. Then, we started radio-tracking of this individual periodically. On 11 December 2007 we located the snake in an underground hole, which had presumably been constructed as a nest tunnel by ants, in the bare sand on the forest floor with a thin litter layer. Because it was close to the end of the expected battery life of the transmitter, we decided to capture the snake again to remove the transmitter. We excavated the ground beginning from the presumptive ant nest entrance (ca $4 \mathrm{~cm}$ in diameter) and found the snake in coiled posture at approximately $28 \mathrm{~cm}$ depth, where a wide, horizontal cavity was present (Fig. 1). While attempting to remove the snake gently from the cavity using a long snake hook, we noticed a clutch of eggs inside the snake's coil. The snake repeatedly emitted a loud hissing sound when the hook contacted its body. We removed both the snake and the clutch, which consisted of eight eggs adherent to each other. One of the eggs was broken accidentally while we attempted to remove the snake. 


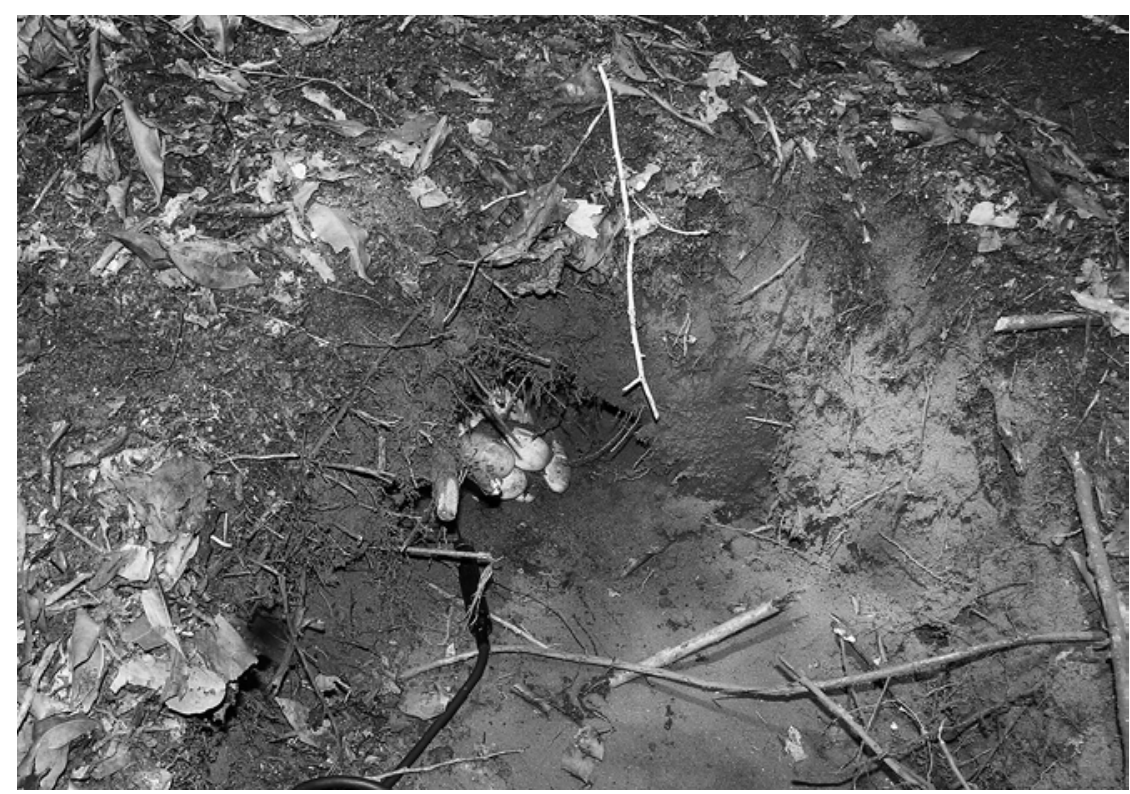

FIG. 1. Excavated oviposition site of Leioheterodon madagascariensis located by radio telemetry. Note that the clutch of eggs has been replaced in its original position for photographing after removing the attending female.

We measured width and length of each egg to the nearest $0.1 \mathrm{~mm}$ using digital calipers and the mass of each egg to the nearest $0.1 \mathrm{~g}$ using an electronic balance. Immediately after these measurements, we returned the intact eggs to their initial position and covered them with sand. Then, we marked the site with a flag for later examination. The female was brought to the camping site to surgically remove the radio-transmitter and was released at the oviposition site on 14 December 2007.

The mean length, width, and mass of the eggs, excluding the broken one, were $53.6 \mathrm{~mm}$, $29.3 \mathrm{~mm}$, and $23.6 \mathrm{~g}$, respectively. We brought the broken egg to a camping site, where we dissected it to find a well-developed embryo (snout-vent length, $225 \mathrm{~mm}$, tail length, $51 \mathrm{~mm}$, body mass, $8.1 \mathrm{~g}$ ). We identified it as Zehr's (1962) stage 36 based on developed pigment pattern, everted hemipenes, head entirely covered by scales, and partially visible brain (Fig. 2). We repeatedly visited and excavated the oviposition site to confirm hatching of the remaining eggs approximately every two weeks

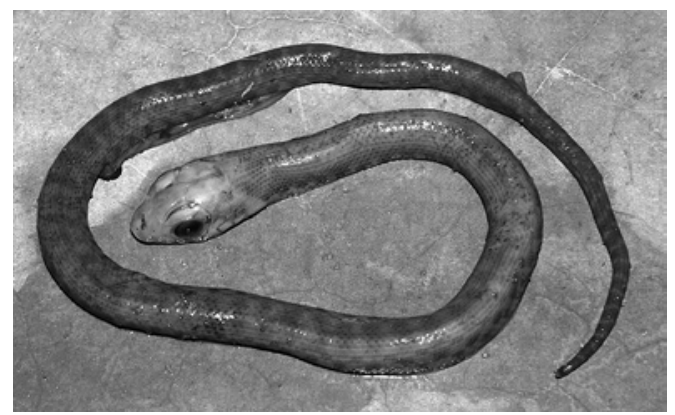

FIG. 2. A stage 36 embryo of Leioheterodon madagascariensis from an accidentally broken egg of the clutch attended by the radio-tagged female.

afterwards until we eventually found the shells of hatched eggs on 26 February 2008. No unhatched eggs remained then. Because the eggs had not yet hatched in the immediately previous examination on 8 February 2008, it is estimated that the eggs hatched 59-77 days after we located them with the attending female. We never discovered the female attending the eggs again after the removal of the radio- 
TABLE 1. Position and behavior of the radio-tracked female Leioheterodon madagascariensis on and after 27 October 2007 when the snake was first located at the oviposition site.

\begin{tabular}{llll}
\hline Date & Site & Behavior & Note \\
\hline 27 Oct 2007 & Oviposition site & Hiding underground (ant nest) & \\
28 Oct 2007 & Oviposition site & Hiding underground (ant nest) & \\
30 Oct 2007 & Oviposition site & Hiding underground (ant nest) & \\
31 Oct 2007 & Oviposition site & Hiding underground (ant nest) & \\
14 Nov 2007 & Trail & Moving (foraing) on ground & ca $100 \mathrm{~m}$ from oviposition site \\
16 Nov 2007 & Oviposition site & Hiding underground (ant nest) & \\
18 Nov 2007 & Oviposition site & Hiding underground (ant nest) & \\
1 Dec 2007 & Site A & Hiding underground (ant nest) & ca $50 \mathrm{~m}$ from oviposition site \\
2 Dec 2007 & Oviposition site & Head protruding from the entrance of hole & \\
7 Dec 2007 & Site A & Basking beside the hole entrance & ca $50 \mathrm{~m}$ from oviposition site \\
8 Dec 2007 & Site A & Hiding underground (ant nest) & ca $50 \mathrm{~m}$ from oviposition site \\
9 Dec 2007 & Site A & Hiding underground (ant nest) & ca $50 \mathrm{~m}$ from oviposition site \\
11 Dec 2007 & Oviposition site & Attending eggs & Presence of eggs was confirmed \\
\hline
\end{tabular}

transmitter.

Based on periodic locations of the female using the radio telemetry, we confirmed that the female used the oviposition site as shelter from at least 27 October 2007 (Table 1). Thereafter, before we found its attendance of eggs, we located the female in two other sites approximately $50 \mathrm{~m}$ and $100 \mathrm{~m}$ away from the oviposition site, respectively. These results collectively indicate shuttling movement of the snake between the oviposition site and other, rather distant areas.

Although there is no direct evidence that the attended eggs were laid by the female that coiled around them, it is highly likely that our observation indicates the maternal attendance of eggs, considering the circumstances. In addition, because $L$. madagascariensis regularly eats reptile eggs (Mori and Randriamahazo, 2002; Glaw and Vences, 2007), the female's attendance of another female's eggs without eating them is highly unlikely.

It is unknown how long the female had attended the eggs when we first found them together, but an estimate can be made based on the following information. The incubation period of eggs of $L$. madagascariensis under captive conditions is reportedly highly variable, ranging from 60-96 days, and such varia- tion is probably partly due to differences in incubation temperature (Conant, 1938; Campbell and Murphy, 1977; Kreutz, 1989; Dathe and Dedekind, 1996; Mori and Tanaka, 2001). In the case of another female collected from a site close to the present nest, incubation to hatching took 86-89 days at approximately 30C (Mori and Tanaka, 2001). Because in the present case the attended eggs hatched 59-77 days after the initial excavation, we suspect that the female's oviposition occurred one week to a few weeks before we found her with the eggs. The well-developed embryo in the broken egg, whose developmental stage was much higher than that at which most snake eggs are laid (Shine, 1983), also supports the idea that the eggs had been attended for a relatively long period before we excavated them.

This estimated duration implies that female L. madagascariensis attend eggs for an extended period, not only for a few days after oviposition. Furthermore, our observation strongly suggests that the female traveled far from the oviposition site at least once and returned to attend the eggs again because we located her at a site $50 \mathrm{~m}$ away two days before excavating the eggs (Table 1). It is almost certain from our observation that maternal attendance of 
eggs by snakes is not always constant, but can be intermittent. This would allow females to feed during the period of parental care, which is an important factor when the cost of parental investment is considered (Gans, 1996).

\section{ACKNOWLEDGEMENTS}

We are grateful to F. Rakotondraparany for his help in arranging and conducting this research project and to A. H. Savitzky for verbal corrections of the manuscript. We also thank Départment de Biologie Animale, Faculté des Sciences, Université d'Antananarivo and l'Association Nationale pour la Gestion des Aires Protégées (ANGAP) for their cooperation in conducting this research. The study was partially supported by a Grant-in-Aid for International Scientific Research Program (nos. 17405008 and 21405007) from the Japan Ministry of Education, Culture, Sports, Science, and Technology and by a Grant for the Global COE Program (A06) to Kyoto University. The field study and collection of specimens were conducted with permission from the Ministry of Forest, Madagascar through ANGAP.

\section{LITERATURE CITED}

CAMPBell, J. A. AND MurPhy, J. B. 1977. Miscellaneous notes on the reproductive biology of reptiles. I. Two colubrid snake species from the Malagasy Republic, Leioheterodon madagascariensis and Madagascariophis colubrina (Reptilia, Serpentes, Colubridae). Journal of Herpetology 11: 228-230.

CLARK, R. W. 2004. Kin recognition in rattlesnakes. Proceedings of the Royal Society of London B (Suppl.) 271: S243-S245.

CONANT, R. 1938. A note on eggs and young of Leioheterodon madagascariensis (Duméril \& Bibron). Zoologica 23: 389-393.

DAthe, F. AND DEDEKIND, K. 1996. Pflege und Vermehrung von Madagaskar-Hakennattern (Leioheterodon madagascariensis Duméril \& Bibron, 1854) im Tierpark Berlin-Friedrichsfelde. Der Zoologische Garten N. F. 66: 69-76.
Duvall, D., SchuetT, G. W., AND ARnOld, S. J. 1993. Ecology and evolution of snake mating systems. p. 165-200. In: R. A. Seigel and J. T. Collins (eds.), Snakes, Ecology \& Behavior. McGraw-Hill Inc., New York.

GANS, C. 1996. An overview of parental care among the Reptilia. p. 145-157. In: J. S. Rosenblatt and C. T. Snowdon (eds.), Parental Care: Evolution, Mechanisms, and Adaptive Significance. Advances in the Study of Behavior. Vol. 25. Academic Press, San Diego.

Glaw, F. AND VENCES, M. 2007. A Field Guide to the Amphibians and Reptiles of Madagascar. 3rd ed. Vences and Glaw Verlag GbR, Köln.

Greene, H. W., May, P. G., Hardy, D. L. Sr., SCITURRO, J. M., AND FARRELl, T. M. 2002. Parental Behavior by Vipers. p. 179-205. In: G. W. Schuett, M. Höggren, M. E. Douglas, and H. W. Greene (eds.), Biology of the Vipers. Eagle Mountain Publ. LC, Eagle Mountain.

KrEUTZ, R. 1989. Zur Kenntnis einiger Nattern aus Madagaskar. Herpetofauna 11: 25-34.

MORI, A. AND RANDRIAMAHAZO, H. J. A. R. 2002. Leioheterodon madagascariensis (Madagascar Menarana snake). Diet. Herpetological Review 33: 57.

MORI, A. AND TANAKA, K. 2001. Preliminary observations on chemical preference, antipredator responses, and prey-handling behavior of juvenile Leioheterodon madagascariensis (Colubridae). Current Herpetology 20: 39-49.

MORI, A., IKEUCHI, I., AND HASEGAWA, M. 2006. Herpetofauna of Ampijoroa, Ankarafantsika Strict Nature Reserve, a dry forest in Northwestern Madagascar. Herpetological Natural History 10: 31-60.

Nishimura, M., AKamine, H., Oyadomari, Y., TAMAKI, H., AND KAMURA, T. 1995. Tracking of Habu by radio telemetry 3. Annual Report of Habu Study Section, Okinawa Prefectural Institute of Health and Environment (18): 111-124. (in Japanese)

REINERT, H. K. AND CUNDALl, D. 1982. An improved surgical implantation method for radio-tracking snakes. Copeia 1982: 702-705.

SHINE, R. 1983. Reptilian reproductive modes: The oviparity-viviparity continuum. Herpetologica 39: $1-8$. 
SHINE, R., SHINE, T., SHINe, J. M., AND SHINE, B. G. 2005. Synchrony in capture dates suggests cryptic social organization in sea snakes (Emydocephalus annulatus, Hydrophiidae). Austral Ecology 30: 805-811.

Somma, L. A. 1990. A categorization and bibliographic survey of parental behavior in Lepidosaurian reptiles. Smithsonian Herpetological
Information Service (81): 1-53.

ZEHR, D. R. 1962. Stages in the normal development of the common garter snake, Thamnophis sirtalis sirtalis. Copeia 1962: 322-329.

Accepted: 30 September 2010 